\title{
Non-canonical Glucocorticoid Receptor Transactivation of gilz by Alcohol Suppresses Cell Inflammatory Response
}

\author{
Hang Pong $\mathrm{Ng}^{1}$, Scott Jennings ${ }^{1}$, Jack Wang ${ }^{1}$, Patricia E. Molina ${ }^{2}$, Steve Nelson ${ }^{3}$ and \\ Guoshun Wang ${ }^{1 *}$

\begin{abstract}
'Alcohol and Drug Abuse Center, Department of Microbiology, Immunology and Parasitology, Louisiana State University Health Sciences Center, New Orleans, LA, United States, ${ }^{2}$ Department of Physiology, Louisiana State University Health Sciences Center, New Orleans, LA, United States, ${ }^{3}$ Department of Medicine, Louisiana State University Health Sciences Center, New Orleans, LA, United States
\end{abstract}

OPEN ACCESS

Edited by:

Jixin Zhong,

Case Western Reserve University,

United States

Reviewed by:

Shanzhong Gong,

University of Texas at Austin,

United States

Yanlin $\mathrm{He}$,

Baylor College of Medicine,

United States

Penghua Yang,

University of Maryland, United States

*Correspondence:

Guoshun Wang

gwang@/suhsc.edu

Specialty section:

This article was submitted

to Inflammation,

a section of the journal

Frontiers in Immunology

Received: 08 April 2017

Accepted: 19 May 2017

Published: 07 June 2017

Citation:

Ng HP, Jennings S, Wang J, Molina PE, Nelson $S$ and Wang $G$ (2017) Non-canonical Glucocorticoid

Receptor Transactivation of gilz by Alcohol Suppresses Cell Inflammatory Response.

Front. Immunol. 8:661. doi: 10.3389/fimmu.2017.00661
Acute alcohol exposure suppresses cell inflammatory response. The underlying mechanism has not been fully defined. Here we report that alcohol was able to activate glucocorticoid receptor (GR) signaling in the absence of glucocorticoids (GCs) and upregulated glucocorticoid-induced leucine zipper (gilz), a prominent GC-responsive gene. Such a non-canonical activation of GR was not blocked by mifepristone, a potent GC competitor. The proximal promoter of gilz, encompassing five GC-responsive elements (GREs), was incorporated and tested in a luciferase reporter system. Deletion and/or mutation of the GREs abrogated the promoter responsiveness to alcohol. Thus, the GR-GRE interaction transduced the alcohol action on gilz. Alcohol induced GR nuclear translocation, which was enhanced by the alcohol dehydrogenase inhibitor fomepizole, suggesting that it was alcohol, not its metabolites, that engendered the effect. Gel mobility shift assay showed that unliganded GR was able to bind GREs and such interaction withstood clinically relevant levels of alcohol. GR knockout via CRISPR/Cas9 gene targeting or GILZ depletion via small RNA interference diminished alcohol suppression of cell inflammatory response to LPS. Thus, a previously unrecognized, non-canonical GR activation of gilz is involved in alcohol modulation of cell immune response.

\section{Keywords: glucocorticoid receptor, glucocorticoid-induced leucine zipper, glucocorticoid, alcohol, LPS, inflammatory response}

\section{INTRODUCTION}

Ethanol, commonly referred to alcohol in everyday life, is the intoxicating ingredient found in beer, wine, and liquor. Alcohol is one of the most consumed substances and affects human health positively or negatively depending on how it is used. Moderate alcohol intake reduces the risk of many adverse health conditions including coronary artery disease, diabetes, hypertension, congestive heart failure, stroke, arthritis, and dementia (1-3). However, alcohol abuse is linked to organ and tissue damage (3-5), which often leads to life-threatening medical complications $(6,7)$. Alcohol has long been recognized as a potent immunosuppressive agent that predisposes individuals to infections by bacteria, fungi, and viruses $(3,8-11)$ and leads to specific defects in innate and adaptive immunity $(6,12)$.

The hypothalamic-pituitary-adrenal (HPA) axis is a major regulatory system of host immunity, which is accomplished by adrenal production of glucocorticoids (GCs) (13). GCs act through 
intracellular interaction with glucocorticoid receptor (GR), a ligand-dependent transcriptional factor that belongs to the superfamily of steroid/thyroid/retinoic acid receptor proteins (14-16). GR signaling is crucial to modulating host immunity. Clinically, steroid therapy is the most prescribed medication for treating chronic inflammatory conditions and autoimmune diseases $(13,17,18)$ and animals with conditional GR-knockout succumb to LPS-induced septic shock (19). GR consists of an aminoterminal transactivation domain, a central DNA-binding domain, and a carboxy-terminus containing the hormone-binding domain as well as sequences related to nuclear translocation, receptor dimerization, and interaction with other cellular proteins (20). In the absence of ligands, GR is sequestered in the cytoplasm by various accessory proteins, including hsp90, hsp70, hsp56, p23, and immunophilins (21). Upon hormonal binding, the receptor undergoes a conformational change and translocates into the cell nucleus where it binds to GC-responsive elements (GREs) in the promoters of GR-targeting genes (22) or tethers with other protein factors (23). Among the GR-targeting genes, Glucocorticoidinduced leucine zipper (GILZ) is a member of the transforming growth factor-beta (TGF- $\beta$ )-stimulated clone-22 (TSC-22) family of transcription factors (24). Direct evidence for the role of GILZ in host immune suppression comes from the naturally evolved inbred SPRET/Ei mice, which are resistant to LPS-induced endotoxemia as a result of an intrinsically increased production of GILZ due to a genetic variation (25). Macrophages with GILZ-knockout lose their LPS tolerance (26). GILZ is reported to transduce the antiinflammatory action of GCs in epithelial cells (27) and redirects the maturation of human dendritic cells to prevent antigen-specific T lymphocyte response (28). Transgenic mice overexpressing GILZ downregulate the Th- 1 and upregulate the Th- 2 responses (29-31). All these data implicate GILZ as a key player in host antiinflammation and immunosuppression (31-33).

Alcohol was reported to elevate plasma GC concentration at the physiological level $(34,35)$, which activates GR signaling through the conventional GC-GR interaction. However, whether alcohol has direct impact on GR signaling at the cellular level is unknown. An early study by Mandrekar and colleagues demonstrated that acute alcohol increases nuclear translocation of non-ligand-bound GR (36). However, whether this unliganded GR has any biological significance was not defined in that study. Our genome-wide analysis of alcohol influence of gene expression demonstrated that acute alcohol upregulates a cluster of GC-responsive genes in a dose-dependent manner (37), including GILZ (TSC22D3) (31), ALOX15B (38), SYNPO2 (39), and PTEN (40), implying that the alcohol-induced non-ligand-bound GR is biologically functional. The current study was designed to delineate the mechanism underlying how alcohol influences GR signaling and activates GC-responsive genes, such as GILZ, in the absence of GC ligands.

\section{MATERIALS AND METHODS}

\section{Chemicals and Reagents}

Common reagents were from Sigma-Aldrich (St. Louis, MO, USA). Alcohol or ethanol (200 proof, absolute ACS/USP Grade) was purchased from Pharmco Products Inc. (Shelbyville, KY, USA). Radioactive $\gamma^{-32} \mathrm{P}$-ATP was obtained from Perkin Elmer (Billerica, MA, USA). All oligonucleotides were ordered from Integrated DNA Technologies (Coralville, IA, USA) and their sequences are displayed in Table $\mathbf{1 .}$

\section{Cell Culture and Alcohol Exposure}

A549 and Mono Mac 6 (MM6) cells were, respectively, cultured in Dulbecco's Modified Eagle Medium (Gibco) and advanced RPMI-1640 (Invitrogen, Carlsbad, CA, USA) supplemented with $10 \%$ fetal bovine serum (FBS) (HyClone, Logan, UT, USA), 2 mM GlutaMax (Gibco), $100 \mathrm{U} / \mathrm{ml}$ penicillin, $100 \mu \mathrm{g} / \mathrm{ml}$ streptomycin, and $0.25 \mu \mathrm{g} / \mathrm{ml}$ amphotericin B. Forty-eight hours before and during experiments, fresh media with $10 \%$ charcoal-stripped FBS (Atlanta Biological) were used to avoid GC interference in experiments. For alcohol exposure, various doses $(0,25$, or $50 \mathrm{mM}$ ) of alcohol were added to the culture media, respectively, and the cells were cultured in the incubators presaturated with the corresponding levels of alcohol.

\section{MM6 Cell Treatments and RT-qPCR for Gilz Expression}

MM6 cells $\left(1.5 \times 10^{6}\right)$ were exposed to alcohol $(0,25$, or $50 \mathrm{mM})$ or $1 \mu \mathrm{M}$ Dexamethasone (Dex) (Sigma-Aldrich) for $24 \mathrm{~h}$ in the presence or absence of $5 \mu \mathrm{M}$ mifepristone (Sigma-Aldrich). The cells were harvested and washed with $1 \times$ PBS twice. Total RNAs were extracted using the Qiagen RNeasy Kit. The cDNAs were synthesized using the Quantitect Reverse Transcriptase Kit (Qiagen). Human GILZ primers (GILZ-F and GILZ-R) and glyceraldehyde 3-phosphate dehydrogenase (GAPDH) primers (GAPDH-F and GAPDH-R) were used at a final concentration of $500 \mathrm{nM}$. The final reaction for each sample was brought to a total volume of $20 \mu \mathrm{l}$ with RT SYBR green qPCR mastermixes (Qiagen). All reactions were carried out in duplicate on a CFX96 system (Bio-Rad Laboratories, Hercules, CA, USA) for quantitative real-time PCR ( $\mathrm{PPCR}$ ) detection. The $\mathrm{qPCR}$ data were

\section{TABLE 1 | Oligonucleotides used in experiments.}

\begin{tabular}{ll}
\hline Name & 'ligonucleotide sequence \\
\hline GILZ-F & 5'-CATGGAGGTGGCGGTCTATC-3' \\
GILZ-R & 5'-CACCTCCTCTCTCACAGCGT-3' \\
Long-GILZp-F & 5'-CGGGGTACGTGCAGAGGGCAAATAATA-3' \\
Short-GILZp-F & 5'-GGGAATTCTGATACCGGCATAACTGCCCTG-3' \\
GlLZp-R & 5'-CCCAAGCTTCGCAGTCCAACCCAGACTC-3' \\
Mut-GRE1-F & 5'-CAAACTAGCGCCAGGTCTACTGAATGCCC-3' \\
Mut-GRE1-R & 5'-GGGCATTCAGTAAGACCTGGCGCTAGTTG-3' \\
Mut-GRE2-F & 5'-GGTGGAACCCAAGAGCACCCTTGGTCCTG-3' \\
Mut-GRE2-R & 5'-CAGGACCAAAGGGTGCTCTTGGGTTCCACC-3' \\
Wt-GRE1(+) & 5'-CAAACTAGCGCTGTTCTTACTGAATGCCC-3' \\
Wt-GRE1(-) & 5'-GGGCATTCAGTAAAGAACAGCGCTAGTTG-3' \\
Mut-GRE1(+) & 5'-CAAACTAGCGCCAGGTCTTACTGAATGCCC-3' \\
Mut-GRE1(-) & 5'-GGGCATTCAGTAAAGACCTGGCGCTAGTTG-3' \\
Wt-GRE2(+) & 5'-GGTGGAACCCAATGTTCTCCTTGGTCCTG-3' \\
Wt-GRE2(-) & 5'-CAGGACCAAAGGAGAACATTGGGTTCCACC-3' \\
Mut-GRE2(+) & 5'-GGTGGAACCCAAGAGCACCCTTGGTCCTG-3' \\
Mut-GRE2(-) & 5'-CAGGACCAAAGGGTGCTCTTGGGTTCCACC-3' \\
GR-E3 (+) & 5'-GAGTTCACTGTGAGCATTC-3' \\
GR-E3 (-) & 5'-GAGGGTAAGGATCAGGTCTTATTG-3'
\end{tabular}


analyzed by the comparative $\mathrm{Ct}(\Delta \Delta \mathrm{CT})$ method. The expression of GILZ of each treated group was compared to that of GAPDH and normalized to the non-treatment group.

\section{Luciferase Plasmid Construction}

The gilz promoter was PCR-amplified from the genomic DNA of primary human airway epithelial cells (Lonza Walkersville, Inc., Walkersville, MA, USA) using the primers (Long-GILZp-F and GILZp-R). The amplicon was cloned into $\mathrm{pCR}^{\mathrm{TM}}$-Blunt II-TOPO ${ }^{\circledR}$ plasmid (Invitrogen), and the primary sequence was verified by DNA sequencing. Then, the obtained $1.94-\mathrm{Kb}$ promoter was excised with KpnI/HindIII and subcloned into the promoterless pGL.4.16[luc2CP/Hygro] plasmid (Promega, Madison, WI, USA), resulting in pGL.4.16-wtGILZ-2p-[luc2CP/Hygro] in which the GILZ promoter drives the expression of the rapidresponse firefly luciferase (Fluc) gene. The cloned promoter contains five GREs. To remove GRE3-5, the region ( $-1,560$ to $-1,884$ ) was deleted using the primers (Short-GILZp-F and GILZp-R). To achieve site-specific mutagenesis of the GRE1 and GRE2 core sequences, QuikChange II Site-Directed Mutagenesis Kit (Agilent Technologies) was used, as instructed by the manufacturer. Synthetic oligonucleotide primers (Mut-GRE1-F, Mut-GRE1-R, Mut-GRE2-F, and Mut-GRE2-R) were used to introduce mutations. All the plasmids with mutagenesis were verified by DNA sequencing.

\section{Dual-Luciferase Reporter Assay}

Transfection was performed with Lipofectamine 2000 Transfection Reagent (Invitrogen, Carlsbad, CA, USA) according to the manufacturer's instruction. Each of the constructed plasmids was cotransfected into A549 cells with the reference plasmid pGL4.73[hRluc/SV40] (Promega) that expresses Renilla luciferase. Forty-eight hours later, the transfected cells were exposed to 0 or $50 \mathrm{mM}$ of alcohol or $1 \mu \mathrm{M}$ Dex for $24 \mathrm{~h}$. Activities of Firefly luciferase and Renilla luciferase were measured using the dual luciferase assay system (Promega). Potency of the wild-type or mutant gilz promoter to drive the reporter luciferase expression was determined by ratio of the activity of Firefly luciferase over that of Renilla luciferase.

\section{Gel Mobility Shift Assay (GMSA)}

Double-stranded oligonucleotides for GRE1 and its flanking region and for GRE2 and its flanking region were prepared and end-labeled with ${ }^{32} \mathrm{P}$ using T4 polynucleotide kinase. GMSA was performed by incubation of recombinant human GR protein (40 ng or $0.5 \mathrm{pmol}$ ) (Sigma-Aldrich), ${ }^{32} \mathrm{P}$-labeled oligonucleotides $(0.5 \mathrm{ng}$ or $0.05 \mathrm{pmol}$ ) and $1 \mu \mathrm{g}$ poly-deoxyinosinic-deoxycytidylic acid (Sigma-Aldrich), in a final volume of $25 \mu$ for each reaction. The GR-GRE complex was resolved by non-denature polyacrylamide gel electrophoresis and detected by X-ray film exposure.

\section{GILZ Knockdown in MM6 Cells}

Lentiviral vectors expressing either siGILZ or siCNTL transgene were constructed as previously described (37) and were produced via triple-plasmid cotransfection of HEK 293T cells (41). Transduction of MM6 cells was carried out at MOI of 5 in the presence of Polybrene (Sigma-Aldrich, $8 \mu \mathrm{g} / \mathrm{ml}$ ). Because the lentiviral vectors had an EGFP marker gene in an independent cassette, each set of vector-transduced cells was sorted through multiple rounds to a pure population.

\section{GR Knockout via CRISPR/Cas9 Gene Targeting}

The S. pyogenes Cas9 plasmid pSpCas9(BB)-2A-GFP (PX458) (Addgene plasmid \# 48138) was a gift from Dr. Feng Zhang at the Massachusetts Institute of Technology. A target-specific sgRNA sequence for Exon 3 of human GR gene was identified using the CRISPR MultiTargeter ${ }^{1}$ and the Zhang lab target finder ${ }^{2}$ online tools. The target sgRNA sequence was cloned into the Cas9 vectors according to the Zhang lab protocol (42). In brief, two single-stranded DNA oligos were designed for the sgRNA target (oligo 1: 5'-CACCGCATTAT-GGAGTCTTAACTTG-3'; oligo 2: 5'-AAACCAAGTTAAGACTCCATAATGC-3'). The pair of oligos was phosphorylated and annealed with T4 Polynucleotide Kinase (NEB). The Cas9 plasmids were digested with BbsI (NEB) and then ligated with the annealed oligos using NEB Quick Ligase. The final constructed plasmids were sequenced for verification. MM6 cells $\left(1.4 \times 10^{6}\right)$ in $300 \mu$ of RPMI 1640 media were combined with $20 \mu \mathrm{g}$ of Cas9-GFP-GR plasmid, incubated on ice for $20 \mathrm{~min}$ and electroporated via exponential decay pulse $(200 \mathrm{~V}$, $975 \mu \mathrm{F})$ using a Bio-Rad Gene Pulser Xcell system. Following electroporation, cells were incubated on ice again for $20 \mathrm{~min}$ and cultured in complete RPMI 1640 overnight. Then, the cells were sorted for GFP-positive population using FACS. The sorted cells were plated on 96-well culture plates at single-cell density. After 7-14 days of growth, cell clones were screened by PCR using GR-E3(+) and GR-E3(-) primers and DNA sequencing to confirm GR gene knockout.

\section{Western Blot Assay}

For nuclear GR measurement, MM6 cells were exposed to alcohol (0 or $50 \mathrm{mM}$ ) or Dex $(1 \mu \mathrm{M})$ for $24 \mathrm{~h}$ in the presence or absence of fomepizole $(4 \mu \mathrm{M})$. The cell nuclei were isolated using Thermo Scientific $^{\mathrm{TM}}$ NE-PER ${ }^{\mathrm{TM}}$ Nuclear and Cytoplasmic Extraction Reagents in accordance with the manufacturer's instruction. The samples were then subjected to Western blot. Rabbit polyclonal antibodies against human GR (Santa Crus Technology, Santa Cruz, CA, USA) and Histone H3 (Cell Signaling Technology, Danvers, MA, USA) were used. Intensities of the GR and Histone H3 bands were estimated by densitometry using NIH Image-J system.

For GILZ measurement, parental MM6, siCNTL-MM6, and siGILZ-MM6 cells were, respectively, treated with 0 or $1 \mu \mathrm{M}$ Dex for $24 \mathrm{~h}$. Cells were collected, harvested, and lysed with $1 \times$ RIPA buffer (Thermo Fisher Scientific, Waltham, MA, USA) supplemented with $1 \times$ protease inhibitor cocktail (Roche, Indianapolis, IN, USA). The cell lysates were collected and subjected to BCA protein assay (Thermo Fisher Scientific, Waltham, MA, USA) for protein concentration. Proteins $(50 \mu \mathrm{g})$ from each sample were loaded onto 10-20\% Tris-Tricine precast gel (Bio-Rad,

\footnotetext{
${ }^{1}$ http://www.multicrispr.net/.

${ }^{2}$ http://crispr.mit.edu/.
} 
Hercules, CA, USA) in the Mini-Protein system (Bio-Rad) for electrophoresis. Rabbit polyclonal anti-human GILZ antibody at 1:200 final dilution (FL-134, Santa Cruz Biotechnology) and rabbit anti- $\beta$-Actin antibody at 1:5,000 final dilution (Cell Signaling Technology, Danvers, MA, USA) were used to probe GILZ and actin.

\section{LPS Stimulation and TNF- $\alpha$ Measurement}

Different genotypes of MM6 cells, as indicated in each experiment, were exposed to alcohol ( 0 or $50 \mathrm{mM}) 1 \mathrm{~h}$ before stimulation with 100 or 1,000 ng/ml LPS from Escherichia coli 0111:B4 (Sigma-Aldrich). The supernatants were collected at different time points. TNF- $\alpha$ was measured by ELISA (R\&D Systems) following the manufacturer's recommendations.

\section{Statistical Analysis}

Statistical analysis was performed with Prism 7.0 (GraphPad Software, La Jolla, CA, USA). A 2-tailed, unpaired Student's $t$-test was used for statistical comparisons. All the data are expressed as mean $\pm \mathrm{SD}$. Difference with $p$-value smaller than 0.05 is considered statistically significant.

\section{RESULTS}

\section{Alcohol Activates GR Signaling via a Non-Canonical Mechanism}

Classical activation of GR signaling is initiated by GC binding to GR that resides in the cytoplasm in complex with various chaperone proteins. Then, GR undergoes a conformational change, dissociates from the complex, and translocates to the nucleus to modulate gene transcription (43). However, our previously published data demonstrated that alcohol upregulates gilz, a prominent GC-responsive gene, in the absence of GC (37), suggesting an alternative GR-activation mechanism under alcohol exposure. To delineate the mechanism, we exposed MM6 cells to various concentrations of alcohol $(0,25$, or $50 \mathrm{mM})$ or dexamethasone (Dex, $1 \mu \mathrm{M})$ for $24 \mathrm{~h}$ in the presence or absence of the GC competitor mifepristone $(5 \mu \mathrm{M})$. Transcription of gilz was assessed by quantitative real-time-PCR. As shown in Figure 1, alcohol $(50 \mathrm{mM})$ significantly upregulated gilz by $\sim 2$-fold. Dex increased gilz expression by $\sim 27$-fold. Importantly, mifepristone completely blocked Dex-activation of gilz, but had no effect on alcohol-activation of gilz. Because Dex is a synthetic GC that activates GR signaling as a GR agonist, while mifepristone a potent competitive GR antagonist, the data indicate that the mechanism for alcohol activation of GR is different from that for GC activation of GR.

\section{Alcohol Activates Gilz Promoter through GR-GRE Interaction}

To define the cis-acting elements that are responsible for alcohol activation of gilz, we cloned the 1.94-kb promoter region of gilz. Primary sequence analysis by the CISTER algorithm method (44) revealed multiple clusters of cis-elements, including GRE, cAMP response element (CRE), Forkhead responsive element (FHRE-1), serum response element (SRE), signaling transducer

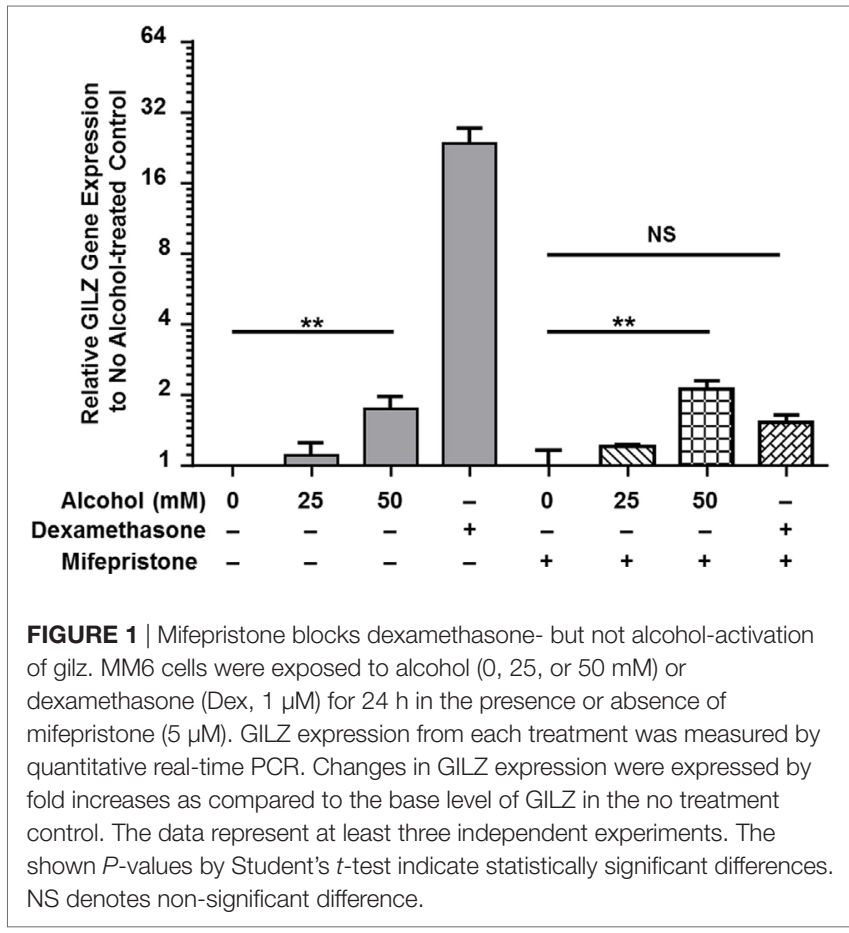

and activator of transcription 6 (STAT-6), GATA Box (GATA), and TATA box (TATA) (Figure S1 in Supplementary Material). Noticeably, there are five GREs, three of which (GRE3, 4, and 5) are relatively distal, and the other two (GRE1 and 2) proximal to the transcriptional initiation site defined by a previous study (45).

To compare Dex-activation of gilz with alcohol activation of gilz, we subcloned the 1.94-kb gilz promoter into the promoter-less pGL.4.16[luc2CP/Hygro] construct, generating the pGL-Long-GILZp-Fluc plasmid (Figure 2A), in which the cloned promoter was designed to regulate the expression of the rapid-response firefly luciferase (Fluc) gene. Because GRE3, 4, and 5 were located closely, we decided to remove them altogether by deletion of the region $(-1,560$ to $-1,884)$, resulting in a shorter gilz promoter and the pGL-Short-GILZp-Fluc plasmid. On the basis of this short promoter construct, we further site-mutated the proximal GRE1 and GRE2 core sequences, producing the pGL-Short-mutGILZp-Luc plasmid (Figure 2A) that had lost all five GREs. A549 cells were, respectively, transfected with one of the three generated plasmids in combination with the reference plasmid pGL4.75-hRluc that constitutively expressed the humanized Renilla luciferase. Forty-eight hours after transfection, the cells were exposed to 0 or $50 \mathrm{mM}$ alcohol or $1 \mu \mathrm{M}$ of Dex for $24 \mathrm{~h}$. Potency of the wild-type or the mutated gilz promoter to drive the reporter gene expression was determined by the activity of the Firefly luciferase that had been normalized to that of the Renilla luciferase in each sample. The data (Figure 2B) demonstrate that the promoter-less pGL.4.16-[luc2CP/Hygro] vector (pGL-vector) did not respond to either Dex or alcohol stimulation. However, the long wild-type gilz promoter with all five GREs (pGL-Long-GILZp) faithfully responded to Dex and alcohol, displaying $\sim 2.3$ - and $\sim 1.6$-fold higher firefly luciferase activity than the non-treatment control. Deletion of GRE3, 4, 


\begin{tabular}{|c|c|c|c|c|c|c|}
\hline GRE-5 & GRE-4 & GRE-3 & GRE-2 & GRE-1 & & \multirow{2}{*}{$\begin{array}{l}\text { pGL-Long- } \\
\text { GILZp-Fluc }\end{array}$} \\
\hline TGTTCT & TGTTCT & TGTCCT & TGTTCT & TGTTCT & Luciferase & \\
\hline \multicolumn{6}{|c|}{ GRE-1 } & \multirow{3}{*}{$\begin{array}{l}\text { pGL-Short- } \\
\text { GILZp-Fluc }\end{array}$} \\
\hline & & & TGTTCT & TGTTCT & Luciferase & \\
\hline \multicolumn{6}{|c|}{ Mutation 2} & \\
\hline & & & GAGCAC & CAGGTC & Luciferase & $\begin{array}{l}\text { pGL-Short- } \\
\text { mutGILZp-Fluc }\end{array}$ \\
\hline
\end{tabular}

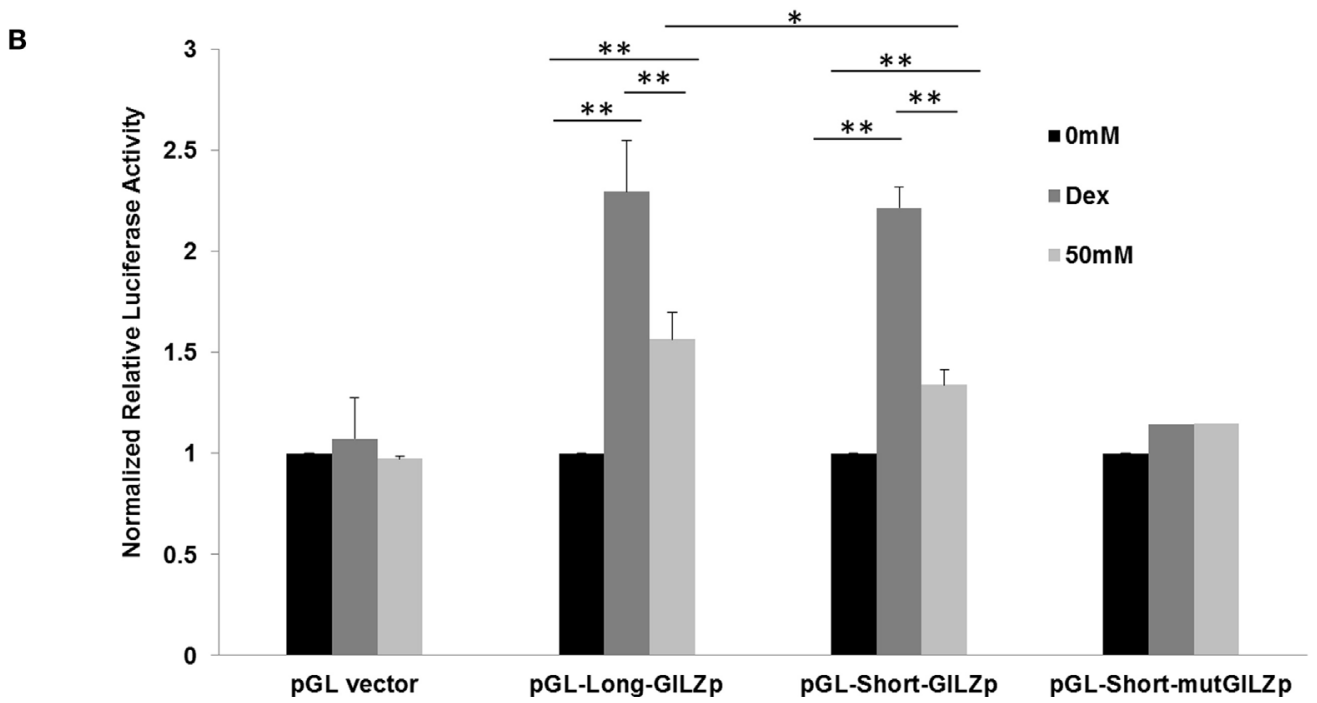

FIGURE 2 | Alcohol activates GILZ promoter via GRE cis-elements. (A) The gilz promoter was cloned into the promoter-less pGL.4.16[luc2CP/Hygro] construct, generating the pGL-Long-GILZp-Fluc plasmid. GRE3-5 sites were removed by deletion of the region $(-1,560$ to $-1,884)$, resulting in the pGL-Short-GILZp-Fluc plasmid. The GRE1 and GRE2 sites were mutated, producing the pGL-Short-mutGILZp-Luc plasmid. (B) A549 cells were, respectively, transfected with one of the three resulting plasmids in combination with the reference plasmid pGL4.75-hRluc that constitutively expressed the humanized Renilla luciferase. Forty-eight hours after transfection, the cells were exposed to 0 or $50 \mathrm{mM}$ alcohol or $1 \mu \mathrm{M}$ of Dex for $24 \mathrm{~h}$. Potency of the wild-type or each mutated gilz promoter to drive the reporter gene expression was determined by the activity of the Firefly luciferase that had been normalized to that of the Renilla luciferase in each sample. Asterisks denote significant differences between the comparing groups by Student's $t$-test $\left({ }^{*} p<0.05,{ }^{* *} p<0.01 ; n=3\right.$ ).

and 5 (pGL-Short-GILZp) significantly reduced the gilz promoter responsiveness to alcohol but not Dex. Further mutations of GRE1 and GRE2 (pGL-Short-mut-GILZp) totally abolished the responsiveness of the promoter to both Dex and alcohol. These data suggest that alcohol bypasses GC to activate gilz promoter through the GRE cis-elements, and that all five GREs appear to be needed for a full action of alcohol. In contrast, the GRE1 and GRE2 are sufficient to convey the full effect of Dex.

\section{Alcohol Instead of Alcohol Metabolites Enhances GR Nuclear Translocation}

Previous publications from our laboratory and others have reported that alcohol induces nuclear translocation of non-ligandbound GR $(35,36)$. However, it is unknown whether this effect is caused by alcohol itself or alcohol metabolites. We exposed MM6 cells to alcohol ( 0 or $50 \mathrm{mM}$ ) for $24 \mathrm{~h}$ in the presence or absence of the alcohol dehydrogenase $(\mathrm{ADH})$ inhibitor fomepizole $(4 \mu \mathrm{M})$. The levels of nuclear GR and Histone H3 for each condition were assessed by Western blot assay and densitometry quantification (Figure 3A). The ratio of nuclear GR over Histone $\mathrm{H} 3$ for each condition was calculated. Data from three separate experiments (Figure 3B) show that alcohol exposure increased nuclear GR as compared to that of the non-alcohol control. Strikingly, fomepizole enhanced GR nuclear translocation. Thus, alcohol-induced GR nuclear translocation is likely the effect of alcohol molecules instead of alcohol-derivatives.

\section{Unliganded GR Is Able to Bind GREs in the Presence of Clinically Relevant Levels of Alcohol}

Alcohol induces GR-GRE interaction in the absence of GC, predicting that non-ligand-bound GR can bind GREs. To prove the prediction, we synthesized and radioactively labeled the double-stranded oligonucleotides covering the core and flanking sequences of GRE1 and GRE2 (Figure 4A). Similarly, the corresponding core-sequence-mutated GRE1 and GRE2 oligonucleotides were also prepared. GMSA was undertaken by incubation of human GR protein with the radioactive oligonucleotides. Non-denaturing polyacrylamide gel electrophoresis revealed that human GR protein without GC coupling formed a GR-GRE 


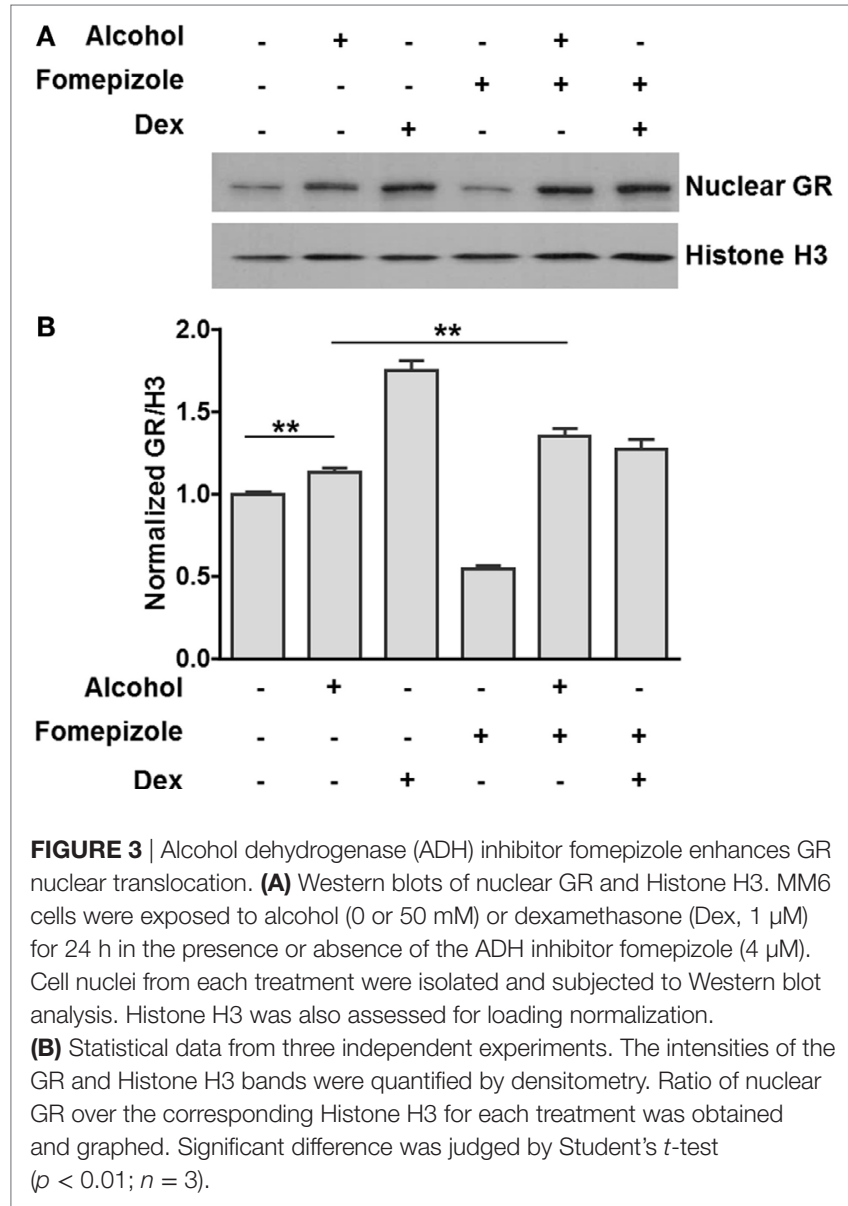

complex with the wild-type GRE1 and GRE2 oligonucleotides, but not the mutant counterparts (Figure 4B). This result proves that non-ligand-bound GR is able to interact with GRE in the absence of ligands.

We further tested if the interaction between the unligandedGR and GRE could withstand alcohol at clinically encountered levels. Human GR protein was incubated with the wild-type GRE1 or GRE2 probe in the presence of alcohol $(0,25,50$, or $100 \mathrm{mM}$ ). GMSA revealed that the non-canonical GR-GRE interaction was strong enough to withstand all the tested levels of alcohol (Figure 4C).

\section{GR Knockout or GILZ Knockdown Diminishes Alcohol Suppression of Cell Inflammatory Response}

To test if gilz gene activation by alcohol through the GR-GRE interaction has any functional alteration, we created a GR-/MM6 cell line by CRISPR/Cas9 gene targeting (Figure 5A), in which a 94-bp insertion mutation was made to GR Exon 3 (Figure S2 in Supplementary Material). Such an insertion led to a premature stop of GR translation and a truncated GR (Figure S3 in Supplementary Material). Then, both GR-/- and GR+/+MM6 cells were exposed to either 0 or $50 \mathrm{mM}$ alcohol, followed by LPS challenge. Twenty-four hours after alcohol exposure, the medium from each condition was collected. Because TNF- $\alpha$ is the key hallmark cytokine induced by LPS $(46,47)$, we elected to use TNF- $\alpha$ as the representative cytokine to indicate the status of the cell inflammatory response. ELISA measurement of TNF- $\alpha$ revealed that without alcohol exposure, both genotypes of MM6 cells produced comparable levels of TNF- $\alpha$ after LPS stimulation (Figure 5B). Alcohol substantially decreased TNF- $\alpha$ production by $\mathrm{GR}+/+$ cells as compared to their non-alcohol control. However, the alcohol suppressive effect on GR-/- cells was significantly attenuated, suggesting GR without ligand coupling is involved in alcohol suppression of cell inflammatory response. To confirm the fidelity of TNF- $\alpha$ in reflecting cell inflammatory response in our experimental system, we were asked to check more inflammatory genes. Toward this end, we checked three more cytokines: IL-1 $\beta$, IL-6, and IL-10. Like TNF- $\alpha$, IL-1 $\beta$, and IL-6 are proinflammatory, while IL-10 is anti-inflammatory. The results demonstrate that alcohol exposure substantially suppressed proinflammatory cytokine (IL-1 $\beta$ and IL-6) production and substantially promoted anti-inflammatory cytokine production by $\mathrm{GR}+/+$ cells. Strikingly, such alcohol effects were diminished in GR-/- cells (Figure S4 in Supplementary Material). These data confirm that TNF- $\alpha$ is a reliable marker to attest inflammatory response in our system and that GR is crucial in alcohol modulation of cell inflammatory response.

We further hypothesized that if GR-activation of gilz is critical to alcohol suppression of cell inflammatory response, depletion of GILZ should resemble deletion of GR, resulting in abrogation of the alcohol suppressive effect. Taking advantage of the already-made GILZ-knockdown (siGILZ) and control (siCNTL) lentiviral vectors (37), we transduced MM6 cells and created a pair of stable cell lines with expression of a normal level of GILZ (siCNTL-MM6) or a diminished level of GILZ (siGILZMM6). To verify GILZ expression in these cells, we performed Western blot assay on the parental MM6, siCNTL-MM6, and siGILZ-MM6 cells stimulated with or without Dex. Because GILZ is a highly GC-responsive gene, Dex application here was to maximally stimulate GILZ expression for the most stringent test of GILZ knockdown. The data (Figure 6A) demonstrate that GILZ $(17 \mathrm{kDa})$ was highly induced by Dex $(1 \mu \mathrm{M})$ in the parental MM6 and siCNTL-MM6 cells. However, the siGILZ-MM6 cells failed to express any detectable level of GILZ, regardless of Dex induction, indicating that the siRNA effectively eradicates GILZ expression in the GILZ-depleted cells.

To examine whether GILZ depletion in the MM6 cells affects alcohol suppression of the cell inflammatory response, we exposed the parental MM6, siCNTL-MM6, and siGILZ-MM6 cells to 0 or $50 \mathrm{mM}$ alcohol, respectively, $1 \mathrm{~h}$ before challenge with LPS at either $100 \mathrm{ng} / \mathrm{ml}$ or $1 \mu \mathrm{g} / \mathrm{ml}$ dose. Twenty-four hours after alcohol exposure, the medium from each condition was collected for TNF- $\alpha$ measurement. As shown (Figure 6B), all three types of cells responded to LPS by producing abundant TNF- $\alpha$ in a LPS dose-dependent fashion. Interestingly, GILZ depletion rendered the siGILZ-MM6 cells more inflammatory, producing more TNF- $\alpha$ as compared to the parental MM6 and siCNTL-MM6 cells under an equal level of stimulation. Alcohol exposure at $50 \mathrm{mM}$ substantially suppressed TNF- $\alpha$ production by the parental MM6 and siCNTL-MM6 cells. However, the alcohol-suppressive 


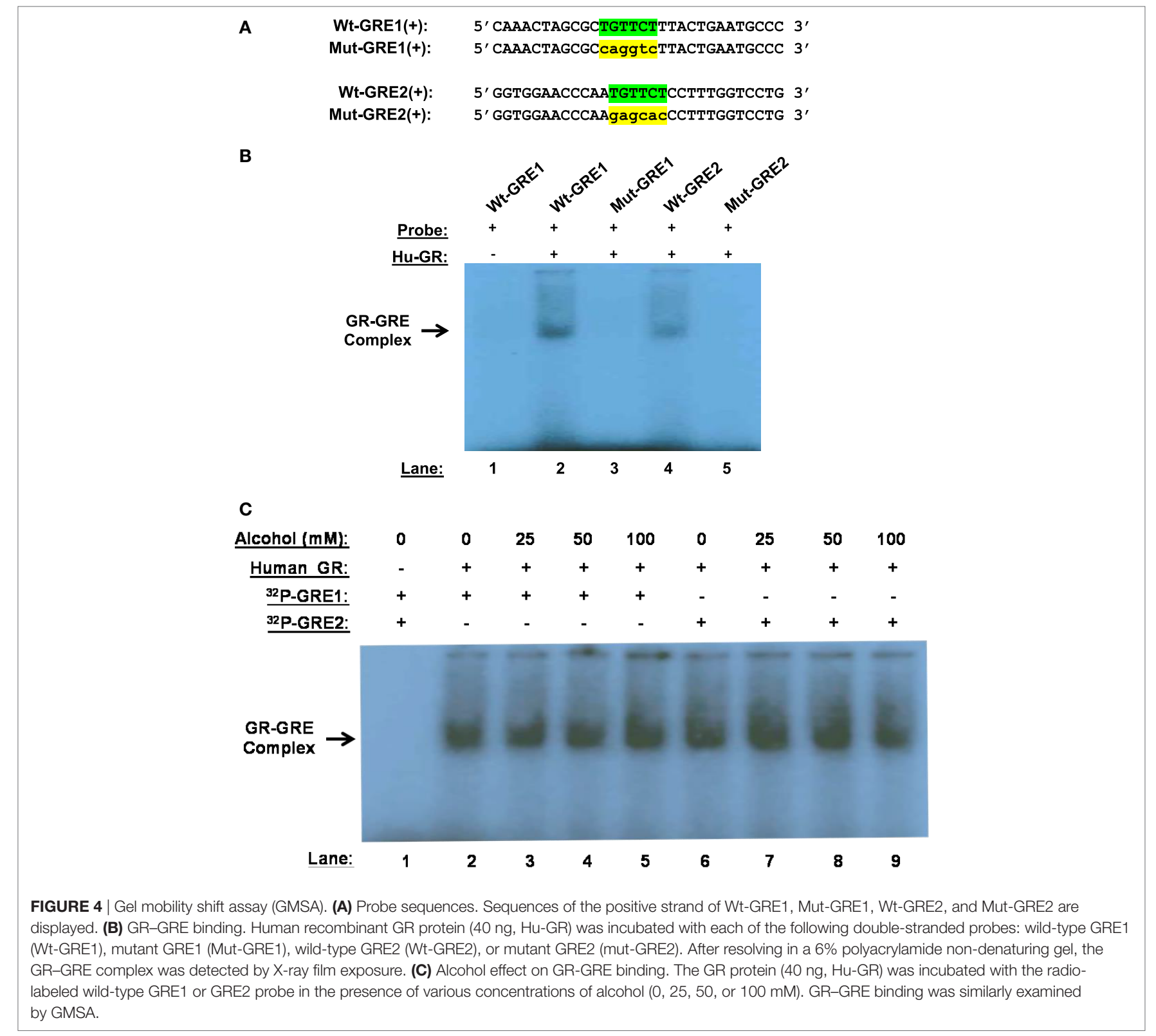

effect was abolished in the GILZ-depleted cells (siGILZ-MM6), suggesting that GILZ is the major player involved in alcohol suppression of cell inflammatory response to LPS.

\section{A Proposed Model for Alcohol Activation of GR Signaling}

Based on the obtained data, we put forward a working model for alcohol activation of GR signaling, as displayed (Figure 7). Conventional GC-activation of GR signaling starts from GR binding by GC ligands, e.g., cortisol. The GR-GC interaction unleashes GR from the confines of chaperone proteins, such as various heat-shock proteins (HSPs), p23, and others. Then, the GC-coupled GR migrates to the cell nucleus to modulate the expressions of GC-responsive genes. In contrast, alcohol interferes with the stability of the GR complex, from which the unliganded GR is released. Such a non-ligand-bound GR is able to interact with GREs in the promoters of GR-targeting genes including gilz. As compared to the conventional GR activation, the alcoholtriggered GR signaling does not involve GCs. This represents a novel non-canonical mechanism for GR activation by alcohol, which may play a pivotal role in alcohol anti-inflammation and immunosuppression.

\section{DISCUSSION}

Alcohol is chemically defined as any organic compound in which a hydroxyl group $(-\mathrm{OH})$ is bound to a carbon atom of an alkyl or substituted alkyl group. Alcohol or ethyl alcohol or ethanol, 


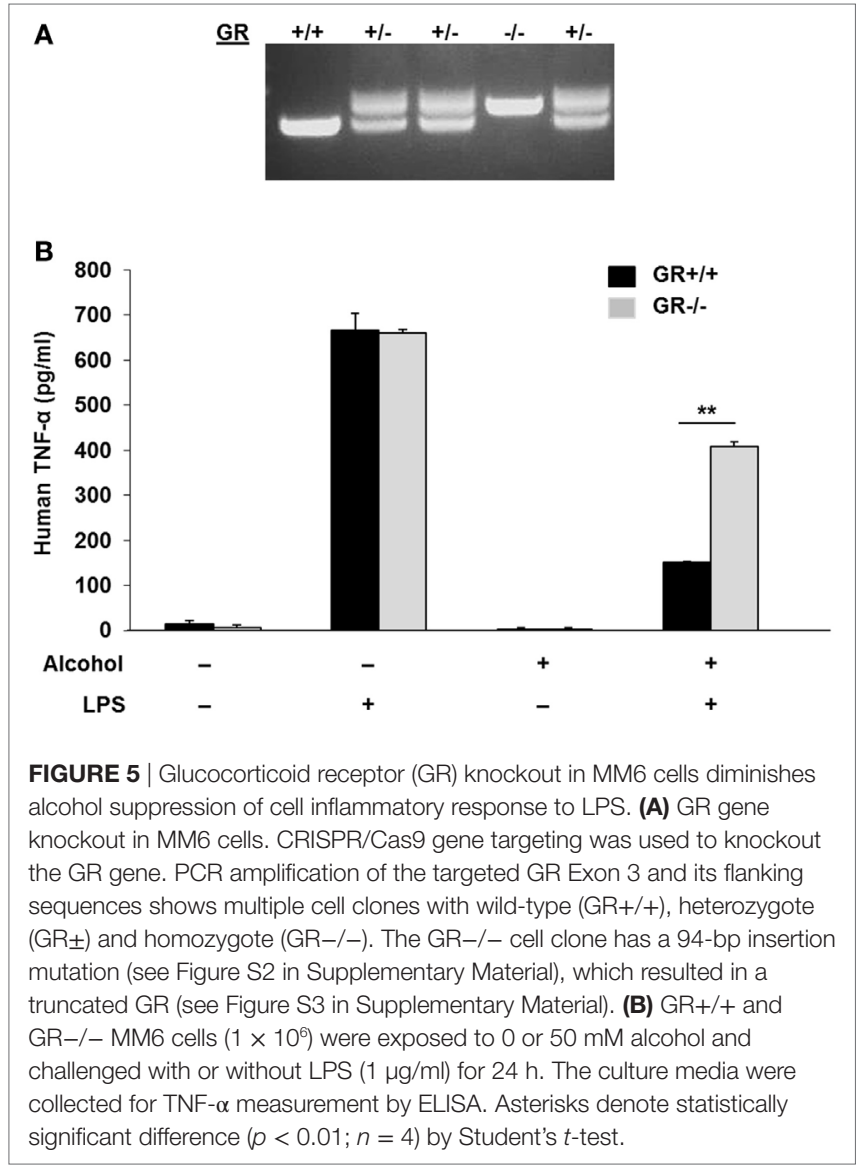

the active component in all wines and alcoholic beverages, is a simple short-chain alcohol. Even though alcohol is the oldest drug used in medicine and a substance widely consumed for leisure and recreation, mechanistic understanding of its many effects on the human body remains remarkably limited. Alcohol has long been known to be anti-inflammatory and immunesuppressive. Examples include that alcohol reduces the development of destructive rheumatoid arthritis (RA), an autoimmune disease characterized by severe joint inflammation $(48,49)$. Moderate alcohol intake was also inversely associated with the risk of systemic lupus erythematosus (SLE), another autoimmune disease $(50,51)$. Alcohol attenuation of the chronic inflammatory diseases resembles the therapeutic effect of steroids. However, the molecular link between alcohol immunosuppression and steroid immunosuppression has not been clearly defined. To our best knowledge, this report provides the first evidence suggesting that alcohol employs an alternative mechanism to activate GR signaling, which may contribute to the long-observed steroid-like effect of alcohol on cell immune response.

The non-ligand-bound GR, induced by alcohol, interacts with GREs and activates gilz, suggesting that the "naked" form of GR has biological activities. This finding presents an exception to the current paradigm that GR has to couple with ligands in order to have transacting capacity. Alcohol is a versatile solvent, miscible with water and with organic solvents. This amphiphilic property grants this molecule the ability to perturb protein-protein interactions that are reliant on weak bonds, such as in the GR complex. GR protein without any GC coupling binds GREs specifically (Figure 4), indicating that ligand binding is not necessarily

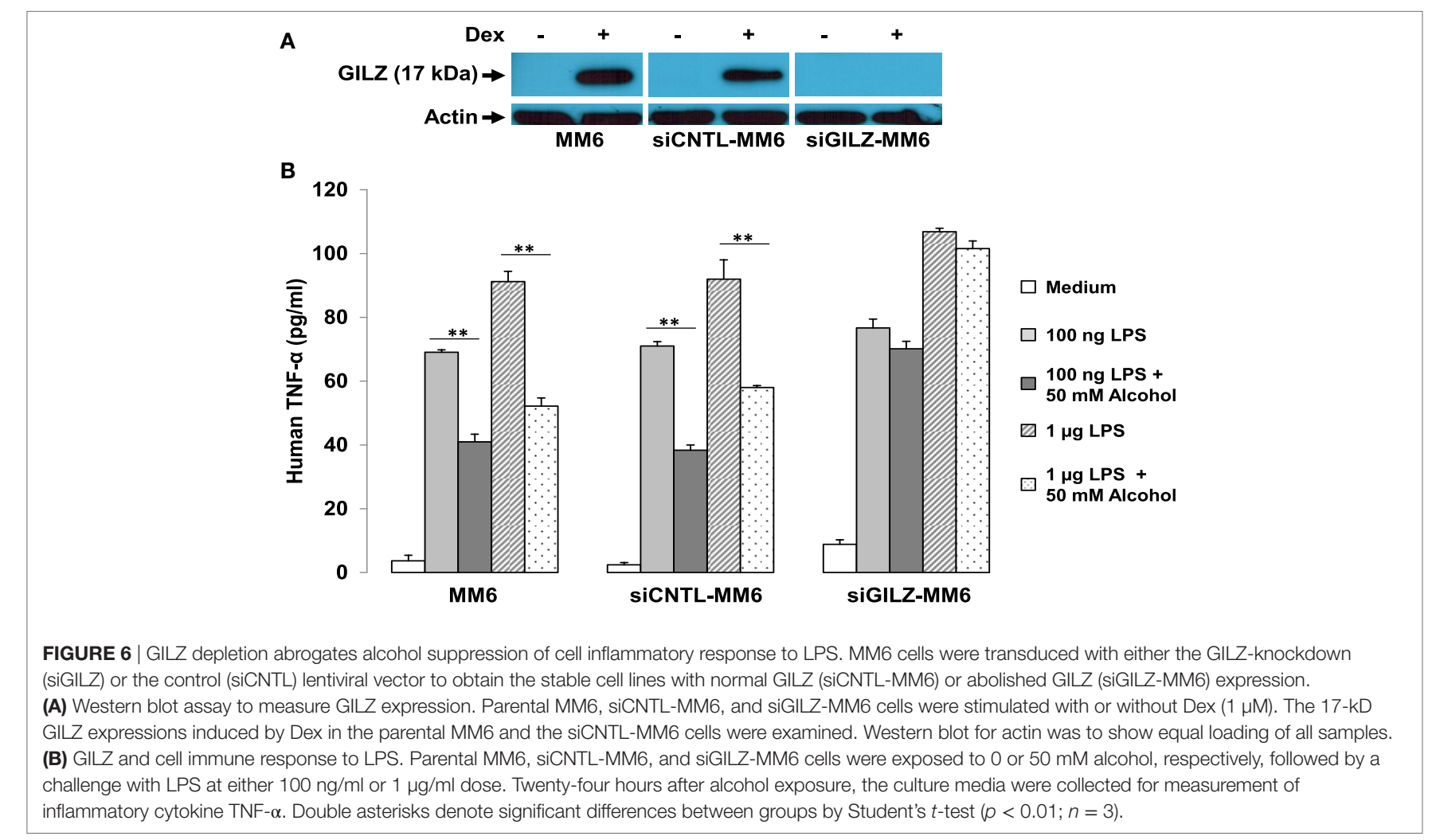




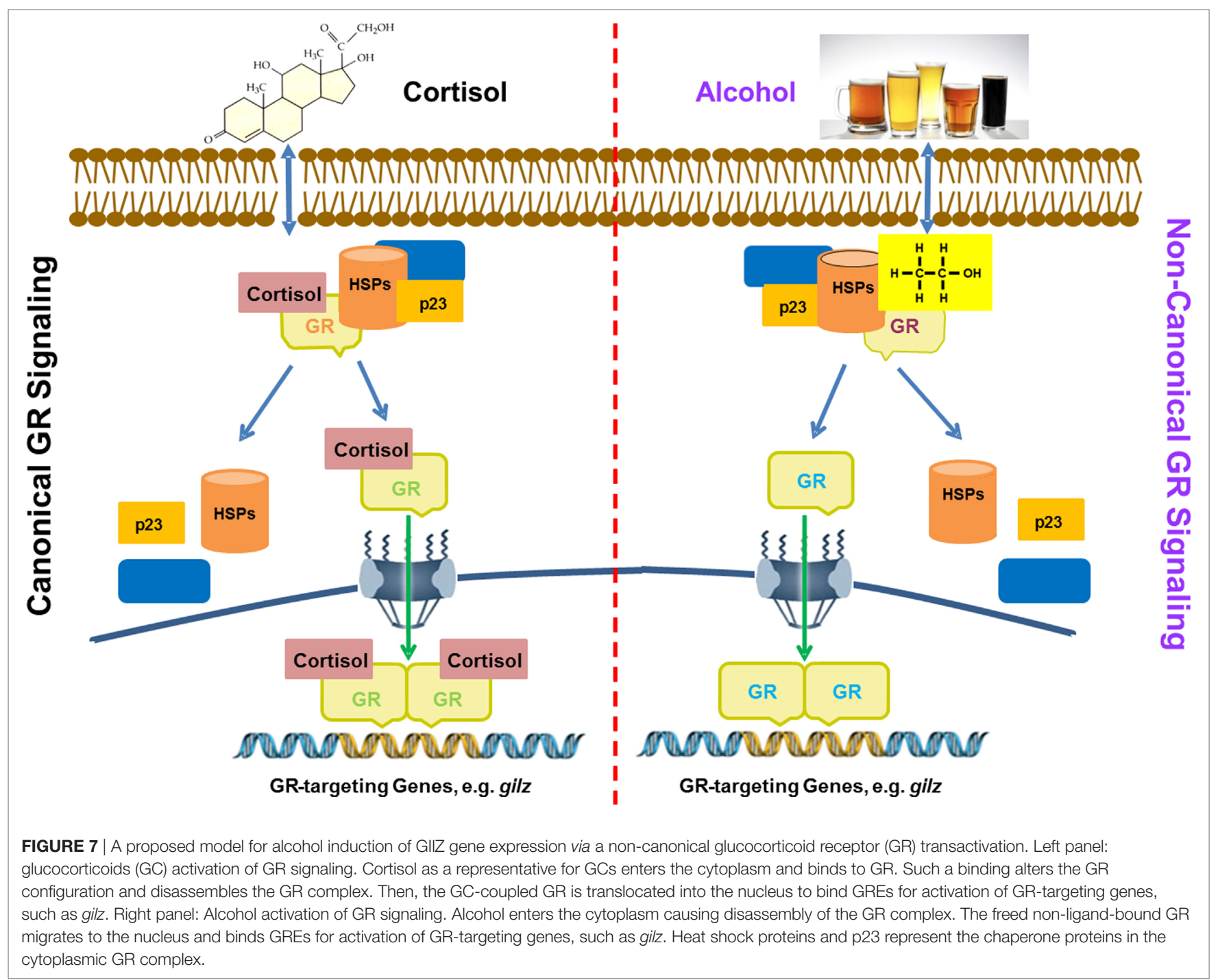

required for GR to interact with GREs. This finding predicts the possibility that any reagents or condition that affects the stability of the GR complex might trigger GR signaling without GC. As a matter of fact, elevations of $\mathrm{pH}$ and temperature, shear stress, and other circumstances are reported to induce GR nuclear translocation in a ligand-independent manner $(21,52,53)$.

GILZ acts as an endogenous carrier that transmits GC therapeutic actions to achieve anti-inflammation and immunosuppression $(31,54-56)$. GILZ expression is reduced or even absent in various inflammatory disorders, such as chronic rhinosinusitis, Crohn's disease, and atherosclerosis $(55,57,58)$. These lines of evidence indicate that suppression of GILZ expression predisposes the host to hyperinflammatory diseases. Contrarily, transgenic expression of GILZ in mice protects the animals from colitis (59). Exogenous supplement of a GILZ peptide suppresses autoimmune encephalomyelitis (60). In the current study, we demonstrated that depletion of GILZ in MM6 cells abolished the alcohol suppressive effect on inflammatory cytokine production elicited by LPS challenge. These data suggest that the GR-GILZ pathway is critical to alcohol anti-inflammation and immunosuppression.
It was noticed that the RT-qPCR data (Figure 1) demonstrate that Dex stimulated GILZ expression by $\sim 27$-fold, while the luciferase assay data (Figure 2) show that Dex only enhanced luciferase expression by $\sim 2.3$-fold in the case of GILZ long promoter (pGL-Long-GILZp). Such a disparity could result from the following inequalities: (1) unlike the natural GILZ promoter, the isolated GILZ promoter used to drive luciferase expression is a minimal promoter that lacks all the enhancers; (2) RT-qPCR is a more sensitive detection method than enzymatic assay; and (3) RT-qPCR measures mRNA abundance, while luciferase assay measures luciferase activity. Nevertheless, the two results are consistent even though not directly comparable.

In Figure 3, the ADH inhibitor fomepizole was used to inhibit alcohol metabolism. We found that with fomepizole application, significantly more GR nuclear translocation was observed, suggesting that alcohol facilitates such a process. We are aware that there exist multiple alcohol oxidation pathways. The most important pathway is $\mathrm{ADH}$-mediated, as $\mathrm{ADH}$ constitute the dominant enzyme system involved in $\sim 80 \%$ of alcohol oxidation (61). The second pathway is through the cytochrome P450 system, also 
called microsomal alcohol oxidizing system or "MEOS" (mostly CYP2E1), which oxidizes only a small fraction of alcohol in the case of acute alcohol exposure. Future experiments are warranted to define how blocking MEOS affects GR translocation.

As illustrated in the proposed model (Figure 7) GR signaling can be activated via the canonical ligand binding or the non-canonical alcohol induction. However, the number of GREs required for each activation appears to be different. We found GRE1 and 2 are sufficient to support a full GC activation of gilz (Figure 2). Nevertheless, all five GREs are needed for a full alcohol activation of gilz. It is noteworthy that in vivo alcohol exposure may lead to concurrent activations of both pathways. It is unknown how the two GR-activation pathways mutually influence each other, which may collectively define the ultimate outcome of the HPA-GR signal transduction under the condition of alcohol exposure.

In summary, we have demonstrated that alcohol activates GR signaling and gilz expression through a non-canonical GR-GRE interaction. This GR-activation mechanism contributes to alcohol modulation of cell inflammatory and immune responses.

\section{REFERENCES}

1. KlonerRA, RezkallaSH.Todrinkornot todrink? That is thequestion.Circulation (2007) 116:1306-17. doi:10.1161/CIRCULATIONAHA.106.678375

2. O'Keefe JH, Bybee KA, Lavie CJ. Alcohol and cardiovascular health: the razor-sharp double-edged sword. J Am Coll Cardiol (2007) 50:1009-14. doi:10.1016/j.jacc.2007.04.089

3. Goral J, Karavitis J, Kovacs EJ. Exposure-dependent effects of ethanol on the innate immune system. Alcohol (2008) 42:237-47. doi:10.1016/j. alcohol.2008.02.003

4. Zakhari S, Li TK. Determinants of alcohol use and abuse: impact of quantity and frequency patterns on liver disease. Hepatology (2007) 46:2032-9. doi:10.1002/hep. 22010

5. Presti RL, Carollo C, Caimi G. Wine consumption and renal diseases: new perspectives. Nutrition (2007) 23:598-602. doi:10.1016/j.nut.2007.04.012

6. Nelson S, Kolls JK. Alcohol, host defence and society. Nat Rev Immunol (2002) 2:205-9. doi:10.1038/nri744

7. Moss M, Burnham EL. Chronic alcohol abuse, acute respiratory distress syndrome, and multiple organ dysfunction. Crit Care Med (2003) 31:S207-12. doi:10.1097/01.CCM.0000057845.77458.25

8. Ruiz M, Ewig S, Marcos MA, Martinez JA, Arancibia F, Mensa J, et al. Etiology of community-acquired pneumonia: impact of age, comorbidity, and severity. Am J Respir Crit Care Med (1999) 160:397-405. doi:10.1164/ ajrccm.160.2.9808045

9. Zisman DA, Strieter RM, Kunkel SL, Tsai WC, Wilkowski JM, Bucknell KA, et al. Ethanol feeding impairs innate immunity and alters the expression of Th1- and Th2-phenotype cytokines in murine Klebsiella pneumoniae. Alcohol Clin Exp Res (1998) 22:621-7. doi:10.1111/j.1530-0277.1998.tb04303.x

10. Szabo G, Dolganiuc A, Dai Q, Pruett SB. TLR4, ethanol, and lipid rafts: a new mechanism of ethanol action with implications for other receptor-mediated effects. JImmunol (2007) 178:1243-9. doi:10.4049/jimmunol.178. 3.1243

11. Zhang P, Bagby GJ, Happel KI, Summer WR, Nelson S. Pulmonary host defenses and alcohol. Front Biosci (2002) 7:d1314-30. doi:10.2741/A842

12. Zhang P, Bagby GJ, Happel KI, Raasch CE, Nelson S. Alcohol abuse, immunosuppression, and pulmonary infection. Curr Drug Abuse Rev (2008) 1:56-67. doi: $10.2174 / 1874473710801010056$

13. Clark AR, Belvisi MG. Maps and legends: the quest for dissociated ligands of the glucocorticoid receptor. Pharmacol Ther (2012) 134:54-67. doi:10.1016/j. pharmthera.2011.12.004

14. Evans RM. Molecular characterization of the glucocorticoid receptor. Recent Prog Horm Res (1989) 45:1-22; discussion 22-7.

\section{AUTHOR CONTRIBUTIONS}

$\mathrm{HN}$ conducted the experiments and analyzed the data. JW made lentiviral constructs and performed the RT-qPCR analyses. SJ did GR gene-knockout and established the GR-/- MM6 cell line. PM and SN provided advice to the project. GW conceived the idea, designed the experiments, and wrote the paper.

\section{FUNDING}

This work was supported by NIH grants to GW (R21AA021824 and R21AA024549) and a pilot grant from LSUHSC Comprehensive Alcohol Research Center funded by NIH grant P60AA09803 (SN and $\mathrm{PM})$.

\section{SUPPLEMENTARY MATERIAL}

The Supplementary Material for this article can be found online at http://journal.frontiersin.org/article/10.3389/fimmu.2017.00661/ full\#supplementary-material.

15. Weinberger C, Hollenberg SM, Ong ES, Harmon JM, Brower ST, Cidlowski J, et al. Identification of human glucocorticoid receptor complementary DNA clones by epitope selection. Science (1985) 228:740-2. doi:10.1126/science.2581314

16. Yamamoto KR. Steroid receptor regulated transcription of specific genes and gene networks. Annu Rev Genet (1985) 19:209-52. doi:10.1146/annurev. genet.19.1.209

17. Busillo JM, Cidlowski JA. The five Rs of glucocorticoid action during inflammation: ready, reinforce, repress, resolve, and restore. Trends Endocrinol Metab (2013) 24:109-19. doi:10.1016/j.tem.2012.11.005

18. Hillier SG. Diamonds are forever: the cortisone legacy. J Endocrinol (2007) 195:1-6. doi:10.1677/JOE-07-0309

19. Bhattacharyya S, Brown DE, Brewer JA, Vogt SK, Muglia LJ. Macrophage glucocorticoid receptors regulate toll-like receptor 4-mediated inflammatory responses by selective inhibition of p38 MAP kinase. Blood (2007) 109:4313-9. doi:10.1182/blood-2006-10-048215

20. Oakley RH, Webster JC, Sar M, Parker CR Jr, Cidlowski JA. Expression and subcellular distribution of the beta-isoform of the human glucocorticoid receptor. Endocrinology (1997) 138:5028-38. doi:10.1210/endo.138.11. 5501

21. Scheschowitsch K, Leite JA, Assreuy J. New insights in glucocorticoid receptor signaling-more than just a ligand-binding receptor. Front Endocrinol (2017) 8:16. doi: $10.3389 /$ fendo.2017.00016

22. Picard D, Yamamoto KR. Two signals mediate hormone-dependent nuclear localization of the glucocorticoid receptor. EMBO J (1987) 6:3333-40.

23. Revollo JR, Cidlowski JA. Mechanisms generating diversity in glucocorticoid receptor signaling. Ann N Y Acad Sci (2009) 1179:167-78. doi:10.1111/j.1749-6632.2009.04986.x

24. D’Adamio F, Zollo O, Moraca R, Ayroldi E, Bruscoli S, Bartoli A, et al. A new dexamethasone-induced gene of the leucine zipper family protects T lymphocytes from TCR/CD3-activated cell death. Immunity (1997) 7:803-12. doi:10.1016/S1074-7613(00)80398-2

25. Pinheiro I, Dejager L, Petta I, Vandevyver S, Puimege L, Mahieu T, et al. LPS resistance of SPRET/Ei mice is mediated by Gilz, encoded by the Tsc22d 3 gene on the X chromosome. EMBO Mol Med (2013) 5:456-70. doi:10.1002/ emmm. 201201683

26. Hoppstadter J, Kessler SM, Bruscoli S, Huwer H, Riccardi C, Kiemer AK. Glucocorticoid-induced leucine zipper: a critical factor in macrophage endotoxin tolerance.J Immunol (2015) 194:6057-67. doi:10.4049/jimmunol.1403207

27. Eddleston J, Herschbach J, Wagelie-Steffen AL, Christiansen SC, Zuraw BL. The anti-inflammatory effect of glucocorticoids is mediated by glucocorticoid-induced leucine zipper in epithelial cells. J Allergy Clin Immunol (2007) 119:115-22. doi:10.1016/j.jaci.2006.08.027 
28. Cohen N, Mouly E, Hamdi H, Maillot MC, Pallardy M, Godot V, et al. GILZ expression in human dendritic cells redirects their maturation and prevents antigen-specific T lymphocyte response. Blood (2006) 107:2037-44. doi:10.1182/blood-2005-07-2760

29. Delfino DV, Agostini M, Spinicelli S, Vacca C, Riccardi C. Inhibited cell death, NF-kappaB activity and increased IL-10 in TCR-triggered thymocytes of transgenic mice overexpressing the glucocorticoid-induced protein GILZ. Int Immunopharmacol (2006) 6:1126-34. doi:10.1016/j.intimp.2006.02.001

30. Cannarile L, Fallarino F, Agostini M, Cuzzocrea S, Mazzon E, Vacca C, et al. Increased GILZ expression in transgenic mice up-regulates Th-2 lymphokines. Blood (2006) 107:1039-47. doi:10.1182/blood-2005-05-2183

31. Ayroldi E, Riccardi C. Glucocorticoid-induced leucine zipper (GILZ): a new important mediator of glucocorticoid action. FASEB J (2009) 23:3649-58. doi:10.1096/fj.09-134684

32. Ayroldi E, Migliorati G, Bruscoli S, Marchetti C, Zollo O, Cannarile L, et al. Modulation of T-cell activation by the glucocorticoid-induced leucine zipper factor via inhibition of nuclear factor kappaB. Blood (2001) 98:743-53. doi:10.1182/blood.V98.3.743

33. Mittelstadt PR, Ashwell JD. Inhibition of AP-1 by the glucocorticoid-inducible protein GILZ. J Biol Chem (2001) 276:29603-10. doi:10.1074/jbc.M101522200

34. Ellis FW. Effect of ethanol on plasma corticosterone levels. J Pharmacol Exp Ther (1966) 153:121-7.

35. Thiagarajan AB, Mefford IN, Eskay RL. Single-dose ethanol administration activates the hypothalamic-pituitary-adrenal axis: exploration of the mechanism of action. Neuroendocrinology (1989) 50:427-32. doi:10.1159/000125259

36. Mandrekar P, Bellerose G, Szabo G. Inhibition of NF-kappa B binding correlates with increased nuclear glucocorticoid receptor levels in acute alcohol-treated human monocytes. Alcohol Clin Exp Res (2002) 26:1872-9. doi:10.1111/j.1530-0277.2002.tb02495.x

37. Gomez M, Raju SV, Viswanathan A, Painter RG, Bonvillain R, Byrne P, et al. Ethanol upregulates glucocorticoid-induced leucine zipper expression and modulates cellular inflammatory responses in lung epithelial cells. J Immunol (2010) 184:5715-22. doi:10.4049/jimmunol.0903521

38. Feng Y, Bai X, Yang Q, Wu H, Wang D. Downregulation of 15-lipoxygenase 2 by glucocorticoid receptor in prostate cancer cells. Int J Oncol (2010) 36:1541-9. doi:10.3892/ijo_00000641

39. Guess A, Agrawal S, Wei CC, Ransom RF, Benndorf R, Smoyer WE. Dose- and time-dependent glucocorticoid receptor signaling in podocytes. Am J Physiol Renal Physiol (2010) 299:F845-53. doi:10.1152/ajprenal.00161.2010

40. Ni Z, Tang J, Cai Z, Yang W, Zhang L, Chen Q, et al. A new pathway of glucocorticoid action for asthma treatment through the regulation of PTEN expression. Respir Res (2011) 12:47. doi:10.1186/1465-9921-12-47

41. Kutner RH, Zhang XY, Reiser J. Production, concentration and titration of pseudotyped HIV-1-based lentiviral vectors. Nat Protoc (2009) 4:495-505. doi:10.1038/nprot.2009.22

42. Ran FA, Hsu PD, Wright J, Agarwala V, Scott DA, Zhang F. Genome engineering using the CRISPR-Cas9 system. Nat Protoc (2013) 8:2281-308. doi:10.1038/nprot.2013.143

43. Hapgood JP, Avenant C, Moliki JM. Glucocorticoid-independent modulation of GR activity: implications for immunotherapy. Pharmacol Ther (2016) 165:93-113. doi:10.1016/j.pharmthera.2016.06.002

44. Wingender E, Chen X, Hehl R, Karas H, Liebich I, Matys V, et al. TRANSFAC: an integrated system for gene expression regulation. Nucleic Acids Res (2000) 28:316-9. doi:10.1093/nar/28.1.316

45. Asselin-Labat ML, David M, Biola-Vidamment A, Lecoeuche D, Zennaro MC, Bertoglio J, et al. GILZ, a new target for the transcription factor FoxO3, protects T lymphocytes from interleukin-2 withdrawal-induced apoptosis. Blood (2004) 104:215-23. doi:10.1182/blood-2003-12-4295

46. Rothe J, Lesslauer W, Lotscher H, Lang Y, Koebel P, Kontgen F, et al. Mice lacking the tumour necrosis factor receptor 1 are resistant to TNF-mediated toxicity but highly susceptible to infection by Listeria monocytogenes. Nature (1993) 364:798-802. doi:10.1038/364798a0
47. Tracey KJ, Beutler B, Lowry SF, Merryweather J, Wolpe S, Milsark IW, et al. Shock and tissue injury induced by recombinant human cachectin. Science (1986) 234:470-4. doi:10.1126/science.3764421

48. Haynes DR. Emerging and future therapies for the treatment of bone loss associated with chronic inflammation. Inflammopharmacology (2006) 14:193-7. doi:10.1007/s10787-006-0006-1

49. Jonsson IM, Verdrengh M, Brisslert M, Lindblad S, Bokarewa M, Islander U, et al. Ethanol prevents development of destructive arthritis. Proc Natl Acad Sci US A (2007) 104:258-63. doi:10.1073/pnas.0608620104

50. Bengtsson AA, Rylander L, Hagmar L, Nived O, Sturfelt G. Risk factors for developing systemic lupus erythematosus: a case-control study in southern Sweden. Rheumatology (Oxford) (2002) 41:563-71. doi:10.1093/ rheumatology/41.5.563

51. Hardy CJ, Palmer BP, Muir KR, Sutton AJ, Powell RJ. Smoking history, alcohol consumption, and systemic lupus erythematosus: a case-control study. Ann Rheum Dis (1998) 57:451-5. doi:10.1136/ard.57.8.451

52. Ji JY, Jing H, Diamond SL. Shear stress causes nuclear localization of endothelial glucocorticoid receptor and expression from the GRE promoter. Circ Res (2003) 92:279-85. doi:10.1161/01.RES.0000057753.57106.0B

53. Sanchez ER. Heat shock induces translocation to the nucleus of the unliganded glucocorticoid receptor. J Biol Chem (1992) 267:17-20.

54. Cheng Q, Morand E, Yang YH. Development of novel treatment strategies for inflammatory diseases-similarities and divergence between glucocorticoids and GILZ. Front Pharmacol (2014) 5:169. doi:10.3389/fphar.2014.00169

55. Hahn RT, Hoppstadter J, Hirschfelder K, Hachenthal N, Diesel B, Kessler SM, et al. Downregulation of the glucocorticoid-induced leucine zipper (GILZ) promotes vascular inflammation. Atherosclerosis (2014) 234:391-400. doi:10.1016/j.atherosclerosis.2014.03.028

56. Hoppstadter J, Diesel B, Eifler LK, Schmid T, Brune B, Kiemer AK. Glucocorticoid-induced leucine zipper is downregulated in human alveolar macrophages upon toll-like receptor activation. Eur J Immunol (2012) 42:1282-93. doi:10.1002/eji.201142081

57. Berrebi D, Bruscoli S, Cohen N, Foussat A, Migliorati G, Bouchet-Delbos L, et al. Synthesis of glucocorticoid-induced leucine zipper (GILZ) by macrophages: an anti-inflammatory and immunosuppressive mechanism shared by glucocorticoids and IL-10. Blood (2003) 101:729-38. doi:10.1182/ blood-2002-02-0538

58. Zhang XH, Lu X, Long XB, You XJ, Gao QX, Cui YH, et al. Chronic rhinosinusitis with and without nasal polyps is associated with decreased expression of glucocorticoid-induced leucine zipper. Clin Exp Allergy (2009) 39:647-54. doi:10.1111/j.1365-2222.2008.03198.x

59. Cannarile L, Cuzzocrea S, Santucci L, Agostini M, Mazzon E, Esposito E, et al. Glucocorticoid-induced leucine zipper is protective in Th1-mediated models of colitis. Gastroenterology (2009) 136:530-41. doi:10.1053/j.gastro.2008. 09.024

60. Srinivasan M, Janardhanam S. Novel p65 binding glucocorticoid-induced leucine zipper peptide suppresses experimental autoimmune encephalomyelitis. J Biol Chem (2011) 286:44799-810. doi:10.1074/jbc.M111.279257

61. Beier JI, McClain CJ. Mechanisms and cell signaling in alcoholic liver disease. Biol Chem (2010) 391:1249-64. doi:10.1515/BC.2010.137

Conflict of Interest Statement: The authors declare that the research was conducted in the absence of any commercial or financial relationships that could be construed as a potential conflict of interest.

Copyright (c) 2017 Ng, Jennings, Wang, Molina, Nelson and Wang. This is an open-access article distributed under the terms of the Creative Commons Attribution License (CC BY). The use, distribution or reproduction in other forums is permitted, provided the original author(s) or licensor are credited and that the original publication in this journal is cited, in accordance with accepted academic practice. No use, distribution or reproduction is permitted which does not comply with these terms. 